\title{
Differential regulation of glucose transporter expression by estrogen and progesterone in Ishikawa endometrial cancer cells
}

\author{
Rodolfo A Medina ${ }^{1}$, Ana Maria Meneses ${ }^{1}$, Juan Carlos Vera ${ }^{2}$, \\ Catherine Gúzman ${ }^{2}$, Francisco Nualart ${ }^{3}$, Federico Rodriguez ${ }^{3}$, \\ Maria de los Angeles Garcia ${ }^{3}$, Sumie Kato ${ }^{4}$, Natalia Espinoza ${ }^{4}$, \\ Carolina Monsó ${ }^{4}$, Andres Carvajall ${ }^{4}$, Mauricio Pinto ${ }^{4}$ and \\ Gareth I Owen ${ }^{4}$
}

${ }^{1}$ Laboratorio de Biología Celular y Molecular, MIFAB, Universidad Nacional Andrés Bello, Republica 217, Piso 4, Santiago, Chile

${ }^{2}$ Departamento de Fisiopatología, Facultad de Ciencias Biológicas, Universidad de Concepción, Barrio Universitario S/N, Concepción, Chile ${ }^{3}$ Departamento de Biología Celular, Facultad de Ciencias Biológicas, Universidad de Concepción, Barrio Universitario S/N, Concepción, Chile ${ }^{4}$ Departamento de Endocrinología, Facultad de Ciencias Biológicas, Pontificia Universidad Católica de Chile, Alameda 340, Santiago, Chile (Requests for offprints should be addressed to R A Medina; Email: rmedina@unab.cl)

\begin{abstract}
Estrogen replacement therapy and other unopposed estrogen treatments increase the incidence of endometrial abnormalities, including cancer. However, this effect is counteracted by the co-administration of progesterone. In the endometrium, glucose transporter (GLUT) expression and glucose transport are known to fluctuate throughout the menstrual cycle. Here, we determined the effect of estrogen and progesterone on the expression of GLUT1-4 and on the transport of deoxyglucose in Ishikawa endometrial cancer cells. Cells were incubated with estrogen, progesterone or combined estrogen and progesterone for $24 \mathrm{~h}$ and the effect on the expression of GLUT1-4 and on deoxyglucose transport was determined. We show that GLUT1 expression is upregulated by estrogen and progesterone individually, but that combined estrogen and
\end{abstract}

progesterone treatment reverses this increase. Hormonal treatments do not affect GLUT2, GLUT3 or GLUT4 expression. Transport studies demonstrate that estrogen increases deoxyglucose transport at Michaelis-Menten constants $\left(K_{\mathrm{m}} \mathrm{s}\right)$ corresponding to GLUT1/4, an effect which disappears when progesterone is added concomitantly. These data demonstrate that different hormonal treatments differentially regulate GLUT expression and glucose transport in this endometrial cancer cell line. This regulation mirrors the role played by estrogen and progesterone on the incidence of cancer in this tissue and suggests that GLUT1 may be utilized by endometrial cancer cells to fuel their demand for increased energy requirement.

Journal of Endocrinology (2004) 182, 467-478

\section{Introduction}

All mammalian cells contain one or more members of the facilitative glucose transporter gene family named GLUT (Joost \& Thorens 2001). These transporters have a high degree of stereoselectivity providing for the bidirectional transport of substrate with passive diffusion down its concentration gradient. GLUTs function to regulate the movement of glucose between the extracellular and intracellular compartments, maintaining a constant supply of glucose available for metabolism (Joost \& Thorens 2001, Medina \& Owen 2002).

The normal human endometrium expresses GLUT1 and GLUT3 and the expression of mRNA and protein of these transporters is increased in the secretory phase of the menstrual cycle when estrogen and progesterone levels are high (von Wolff et al. 2003). The normal rat uterus expresses GLUT1 and GLUT4. In this tissue, glucose transport and GLUT1 mRNA and protein expression are increased by estrogen treatment (Welch \& Gorski 1999). These and other data indicate that an adequate endometrial glucose metabolism, mediated by GLUTs, is necessary for endometrial proliferation, differentiation and decidualization. However, aberrant expression of these transporters is found in a wide spectrum of endometrial epithelial malignancies (Binder et al. 1997, Wang et al. 2000, Medina \& Owen 2002), indicating that GLUT expression and glucose transport may be involved in carcinogenesis.

There are extensive data linking sex steroid hormones, estrogen and progesterone, to the genesis of endometrial 
cancer (Henderson et al. 1982, Key \& Pike 1988). Recent clinical studies have demonstrated that postmenopausal women receiving hormone replacement therapy (HRT) containing only estrogen are at higher risk for this type of cancer (Persson 2002). When progesterone is added to HRT preparations, the estrogen-induced increase in endometrial cancer incidence is reduced (Schairer et al. 2000). The same pattern is observed with estrogen only versus combined estrogen and progesterone oral contraceptives (Henderson \& Feigelson 2000). This indicates that progesterone counteracts the cancer-inducing effects of estrogen on the endometrium. In this paper we have attempted to further dissect the behavior of progesterone and estrogen by examining the hormonal regulation of a family of glucose transporters, which have previously been implicated in cancer, in an endometrial cancer cell line.

Analysis of biopsy samples has demonstrated that GLUTs are overexpressed in a variety of cancers including tumors from estrogen and progesterone target tissues such as breast and ovary. Furthermore, this overexpression of GLUT family members is correlated with poor patient prognosis (Medina \& Owen 2002). Therefore, we hypothesized that if GLUT expression were related to the aforementioned HRT clinical phenotype, estrogen, progesterone and combined therapy should differentially regulate glucose transporters in the endometrium. In order to test this hypothesis, we used the well characterized endometrial cancer cell line, Ishikawa, to study hormonal regulation of GLUTs and glucose transport. This cell line stably expresses all paralogues and isoforms of the estrogen and progesterone receptors respectively, and responds to steroid hormones in a similar manner to the situation in vivo.

Results presented herein demonstrate that GLUT1-4 family members are expressed in the Ishikawa cell line and that GLUT1 and possibly GLUT4 are regulated to varying degrees by $17 \beta$-estradiol and progesterone. GLUT1 is the predominant form expressed, while GLUT2 is expressed at low levels in the endometrial cancer cells. Interestingly, GLUT1 expression correlates with the clinical phenotype observed in the endometrium in response to hormone treatment. GLUT1 expression, and the glucose transport mediated by this transporter, is increased by $17 \beta$-estradiol and progesterone. This increase is reversed when the cells are exposed to a combined $17 \beta$-estradiol+progesterone treatment. These data support our theory that differential regulation in the access to an available energy substrate, in the form of glucose, confers a survival advantage to these burgeoning cancer cells and increases the risk of endometrial abnormalities such as cancer. This energy is delivered by a $17 \beta$-estradiol- or progesterone-induced increase in GLUT expression and glucose transport in Ishikawa endometrial cancer cells, an effect which disappears when both hormones are administered concomitantly.

\section{Materials and Methods}

\section{Cell culture and hormonal treatment}

Cells were grown in DMEM/F12 media supplemented with $10 \%$ fetal bovine serum as previously published (Medina et al. 2003). Briefly, depending on the experiment, cells were plated in tissue culture Petri dishes or 12 -well plates (Nunc, Rochester, NY, USA), until 80\% confluence, and then the medium was changed to DMEM/F12 medium containing 5\% charcoal-treated serum for $24 \mathrm{~h}$. Cells were divided into four groups: control, estrogen, progesterone and combined estrogen and progesterone. 17 $\beta$-Estradiol and progesterone (Sigma, St Louis, MO, USA) were dissolved in ethanol and added to the cells, individually or in combination, to a final concentration of $10 \mathrm{nM}$ for a period of $24 \mathrm{~h}$. For the PCR experiments, hormonal treatment was administered for periods of 6, 9 or $24 \mathrm{~h}$. Ethanol vehicle was used as control.

\section{Western blotting}

Cells were harvested from Petri dishes in cold PBS and the pellet was resuspended in lysis buffer $(0.4 \mathrm{M} \mathrm{KCl}, 20 \mathrm{mM}$ Hepes $\mathrm{pH} 7 \cdot 4,1 \mathrm{mM}$ dithiothreitol, 20\% glycerol). After sonication on ice, the lysate was centrifuged at $14000 \mathrm{~g}$ for 20 min at $4{ }^{\circ} \mathrm{C}$ in order to separate membrane (pellet) and cytosolic (supernatant) fractions. The crude membrane fraction was resuspended in the lysis buffer mentioned above and protein concentration was determined by the Bradford assay and confirmed by Ponceau S staining of the membrane after wet blot transfer. For GLUT1-3 detection, $100 \mu \mathrm{g}$ crude membrane extract were loaded in each lane, separated by polyacrylamide gel electrophoresis in the presence of sodium dodecylsulfate, transferred to nitrocellulose membranes, and incubated overnight with anti-GLUT1-4 affinity purified antibodies (1:1000; Alpha Diagnostic, San Antonio, TX, USA). Goat anti-rabbit IgG secondary antibody coupled to hydrogen peroxidase (1:3000, Bio-Rad Laboratories, Hercules, CA, USA) was applied for one hour at room temperature. The reaction was developed by chemiluminescence (ECL, Western Lightning, NEN Life Science Products, Perkin-Elmer, Boston, MA, USA). Semi-quantitative densitometry of the bands was performed using the NIH Scion Image 1.62c software package for Macintosh. Positive controls used were: GLUT1, skeletal muscle; GLUT2, liver; GLUT3, spermatozoid; GLUT 4, heart (neither the GLUT4 positive control (data not shown), nor the Ishikawa samples provided a clean Western blot).

\section{Immunocytochemistry}

Immunocytochemistry studies were carried out as previously described (Nualart et al. 1999). Briefly, after 24-h hormonal treatment the cells were fixed with $4 \%$ 
formaldehyde (in PBS) for $30 \mathrm{~min}$ at room temperature. Cells were then permeabilized in PBS containing 1\% bovine serum albumin (BSA) and 0.1\% Triton X-100 for $10 \mathrm{~min}$ at room temperature. The cells were incubated with the anti-GLUT1, anti-GLUT3 and anti-GLUT4 antibody (1:500, Alpha Diagnostic) overnight at room temperature. Cells were then incubated with fluoresce isothiocyanate (FITC)-conjugated rabbit anti-mouse IgG (1:200, Roche Molecular Biochemicals, Indianapolis, IN, USA) for $2 \mathrm{~h}$, mounted, and analyzed by fluorescence microscopy. As controls, we utilized primary antibodies pre-absorbed with the respective peptides used to raise them.

\section{$R T-P C R$}

Total RNA was isolated from cells using the Chomczynski method (Chomczynski 1992). cDNA was generated using reverse transcriptase (Superscript II, Invitrogen, Carlsbad, CA, USA). Using previously published methods and GLUT1-4 primers (Takagi et al. 1994), semi-quantitative PCR reactions were performed from cDNA generated from ethanol vehicle, estrogen- $(10 \mathrm{nM})$, progesterone$(10 \mathrm{nM})$, and combined estrogen-progesterone (10 nM each)-treated samples, using Taq polymerase (Invitrogen). Cycle curves for all sets of PCR primers were performed. The number of cycles performed for each primer set was in the linear range of the curve (GLUT1, 30 cycles; GLUT2, 40 cycles; GLUT3, 28 cycles; GLUT4, 40 cycles). As an internal control, primers amplifying a region of glucose-6-phosphate dehydrogenase (GAPDH) were used.

\section{Deoxyglucose transport}

Two types of transport experiments were carried out. In the time-course experiment, uptake was measured over time using a constant concentration of the substrate, $\left[{ }^{3} \mathrm{H}\right] 2$-deoxy-D-glucose (DOG). For the concentration dependence experiment, uptake was measured at a fixed time $(30 \mathrm{~s})$ at different concentrations of DOG. The transport experiments were performed using cell monolayers growing attached to the bottom of 12-well tissue culture plates. The standard transport medium contained $15 \mathrm{mM}$ Hepes buffer pH 7·6, $135 \mathrm{mM} \mathrm{NaCl}, 5 \mathrm{mM} \mathrm{KCl}$, $1.8 \mathrm{mM} \mathrm{CaCl}_{2}, 0.8 \mathrm{mM} \mathrm{MgCl}_{2}$, and the substrate DOG at the concentrations indicated in the Figures. Monolayers were washed twice with substrate-free transport medium to eliminate all traces of culture medium, and then incubated for $1 \mathrm{~h}$ at room temperature in the same solution to deplete the cells of intracellular glucose. Uptake experiments were initiated by replacing the medium with $0 \cdot 2 \mathrm{ml}$ transport medium containing $1 \cdot 0 \mu \mathrm{Ci}$ DOG, followed by incubation at room temperature during the time required. Uptake was terminated by adding $2 \mathrm{ml}$ ice-cold stopping solution (15 mM Hepes buffer $\mathrm{pH}$ 7·6, $135 \mathrm{mM}$
$\mathrm{NaCl}, 5 \mathrm{mM} \mathrm{KCl}, 0.8 \mathrm{mM} \mathrm{MgSO}{ }_{4}, 1.8 \mathrm{mM} \mathrm{CaCl}_{2}$, $0.2 \mathrm{mM} \mathrm{HgCl} 2$ ). The monolayers were then rinsed twice with $2 \mathrm{ml}$ stop solution and lyzed in $0.2 \mathrm{ml}$ lysis solution $(10 \mathrm{mM}$ Tris $-\mathrm{HCl} \mathrm{pH} 8 \cdot 0,0 \cdot 2 \% \mathrm{SDS})$. The samples were added to $2 \mathrm{ml}$ scintillation cocktail for radioactivity determination. The data in Figs 4-6 are corrected data obtained after subtracting the respective control values from experiments performed at $4{ }^{\circ} \mathrm{C}$. Statistical analysis was performed using the Student's $t$-test method. Statistical significance was set at $P<0 \cdot 05$.

\section{Results}

\section{GLUT isoform expression}

Mammalian cells differentially express GLUT isoforms. Our aim was to study the expression of GLUT isoforms present in the Ishikawa endometrial cancer cell line. For the purposes of this paper, only the expression of the GLUT1-4 isoforms was studied. Western blotting and immunocytochemistry analysis demonstrated the presence of GLUT1-4 in these cell lines (Figs 1 and 2).

\section{Hormonal regulation of GLUT protein expression}

Western blotting and immunocytochemistry studies show that hormonal treatments differentially regulated GLUT expression in this cell line (Figs 1 and 2). 17 $\beta$-Estradiol treatment produced the highest expression of GLUT1 (3.2-fold), with progesterone showing a mild increase (1.7-fold) and combination therapy actually showing a decrease as compared with control (Fig. 1A,B). The GLUT1 results were confirmed by flow cytometry studies (data not shown). Unfortunately GLUT2, GLUT3 and GLUT4 antibodies were incompatible with flow cytometry. GLUT2 and GLUT3 expression was very low and no changes were observed in response to hormonal treatment (Figs 1 and 2). The GLUT3 results were confirmed by immunocytochemistry (Fig. 2). Several GLUT4 antibodies (Santa Cruz, Alpha Diagnostics) were tried for Western blotting, but none of them proved compatible with this technique. For this reason we decided to perform immunocytochemistry studies for this transporter. Results showed that GLUT4 is slightly upregulated by all hormonal treatments, although the lack of clear differences in staining made these data difficult to interpret (Fig. 2).

\section{GLUT mRNA expression}

The aforementioned data demonstrated that hormonal preparations regulated GLUT1 and possibly GLUT4 protein expression in Ishikawa cells. Therefore, we investigated if these observed changes were manifested at the level of RNA. To this end, we performed RT-PCR with primers designed to unique sequences in GLUT1-4. None of the hormonal treatments, lasting for 9 (Fig. 3A), 6 (Fig. 3B) or 24 h (Fig. 3C), affected GLUT1-4 RNA expression. As a positive control of this technique for 
A

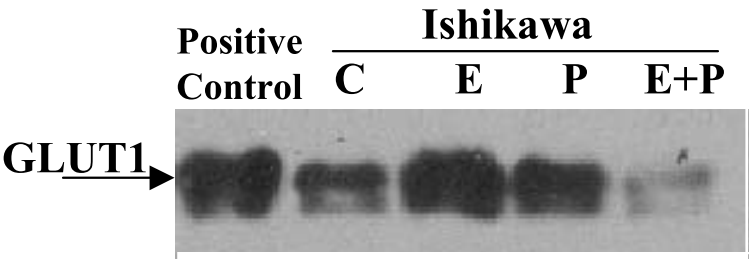

GLUT2

GLUT3

B

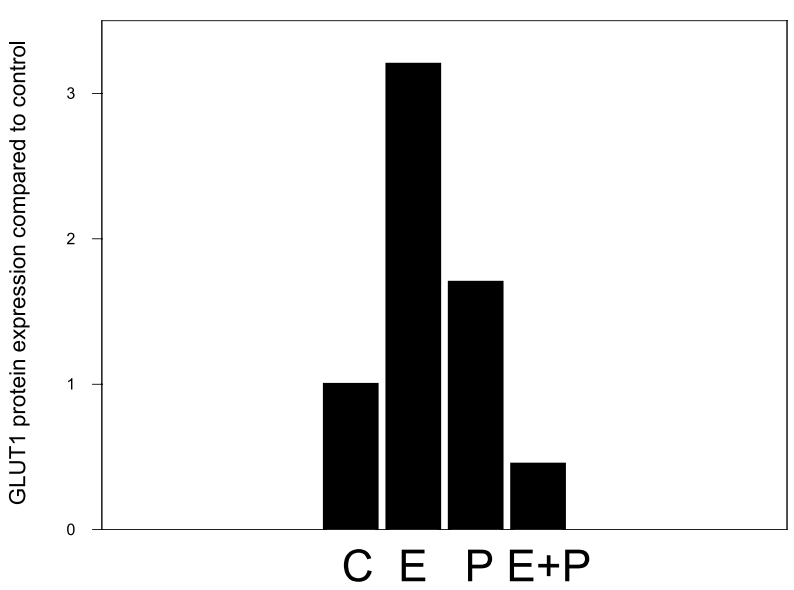

Figure 1 Western blots for GLUT protein expression in control and hormone-treated Ishikawa cells. (A) Western blots showing the effect of 24-h incubation with $10 \mathrm{nM}$ estrogen (E), $10 \mathrm{nM}$ progesterone $(\mathrm{P})$ and $10 \mathrm{nM}$ estrogen $+10 \mathrm{nM}$ progesterone $(\mathrm{E}+\mathrm{P})$ on GLUT1, GLUT2 and GLUT3 expression. Control cells (C) were incubated with a corresponding volume of ethanol which was the vehicle used to solubilize the hormones. Positive controls used were: GLUT1, skeletal muscle; GLUT2, liver; GLUT3, spermatozoid. (B) Histogram showing the effects of 24-h incubation with $10 \mathrm{nM}$ estrogen $(E), 10 n M$ progesterone $(P)$ and $10 \mathrm{nM} \mathrm{E+10nM} \mathrm{P}$ $(\mathrm{E}+\mathrm{P})$ on GLUT1 expression.

measuring hormonal regulation we used the ZR-75 breast cancer cell line (Medina et al. 2003). In the ZR-75 cell line, but not in Ishikawa, treatment with progesterone, but not $17 \beta$-estradiol, regulated GLUT3 mRNA expression (Fig. 3D).

\section{Glucose transport}

Next, we asked whether the changes in expression of GLUT1-4, observed in hormone-treated cells, were accompanied by an alteration in the capacity of these cells to transport glucose. To this end, we measured the transport of DOG, a glucose analog that is a specific substrate of the facilitative glucose transporters. In initial experiments, we used short transport assays and three different DOG concentrations to assess the contributions to transport of the different glucose transporters expressed in the Ishikawa cells: $0.1 \mathrm{mM}$ for GLUT3 (transport Michaelis-Menten constant $\left.\left(K_{\mathrm{m}}\right)<1 \mathrm{mM}\right), 5 \mathrm{mM}$ for GLUT1 and GLUT4 (transport $K_{\mathrm{m}}$ of $3-5 \mathrm{mM}$ ), and $15 \mathrm{mM}$ for GLUT2 (transport $K_{\mathrm{m}}$ of $15-20 \mathrm{mM}$ ).

A time-course analysis of DOG uptake using substrate concentrations of $0 \cdot 1,5$ and $15 \mathrm{mM}$ DOG revealed that the transport rate was linear for at least $60 \mathrm{~s}$ at each tested concentration, which indicates that these rates represent real transport rates (Fig. 4). In Ishikawa cells at $0.1 \mathrm{mM}$ DOG, time-course analysis showed that the rate of DOG transport under control conditions was $0 \cdot 13 \pm 0 \cdot 01 \mathrm{nmol} /$ $\min \times 10^{6}$ cells (Fig. 4A). This transport was increased by $17 \beta$-estradiol (DOG transport rate of $0 \cdot 15 \pm 0 \cdot 01 \mathrm{nmol} /$ min $\times 10^{6}$ cells; $\left.P<0 \cdot 05\right)$ (Fig. $4 \mathrm{~A}$ ). Progesterone (DOG transport rate of $0.11 \pm 0.02 \mathrm{nmol} / \mathrm{min} \times 10^{6}$ cells) (Fig. $4 \mathrm{~B})$ and combined $17 \beta$-estradiol and progesterone treatments (DOG transport rate of $0 \cdot 12 \pm 0.01 \mathrm{nmol} / \mathrm{min} \times$ $10^{6}$ cells) (Fig. 4C) did not significantly affect DOG transport. These transport results reflect the low GLUT3 protein expression levels. At $5 \mathrm{mM}$ DOG, time-course analysis showed that the rate of DOG incorporation under control conditions was $1.2 \pm 0.04 \mathrm{nmol} / \mathrm{min} \times 10^{6}$ cells (Fig. 4D). The rate of DOG uptake was significantly increased by $17 \beta$-estradiol $\left(1.8 \pm 0.07 \mathrm{nmol} / \mathrm{min} \times 10^{6}\right.$ cells; $P<0.05$ ) (Fig. 4D). This increase was slightly less with progesterone $\left(1.7 \pm 0.05 \mathrm{nmol} / \mathrm{min} \times 10^{6}\right.$ cells; $P<0 \cdot 05$ ) (Fig. 4E). Interestingly, combined $17 \beta$-estradiol plus progesterone completely abolished the increases in DOG transport observed with both $17 \beta$-estradiol and progesterone individually $\left(1.2 \pm 0.03 \mathrm{nmol} / \mathrm{min} \times 10^{6}\right.$ cells; not significant) (Fig. 4F). These results are well correlated with GLUT1 protein expression data. Since GLUT1 and GLUT4 have overlapping $K_{\mathrm{m}} \mathrm{s}$ for DOG transport, it is impossible to discern the individual contributions of GLUT1 and GLUT4 to transport at this DOG concentration. At $15 \mathrm{mM}$ DOG, time-course analysis shows that the rate of DOG incorporation under control conditions was $2 \cdot 1 \pm 0 \cdot 25 \mathrm{nmol} / \mathrm{min} \times 10^{6}$ cells (Fig. 4G). Neither $17 \beta$-estradiol (DOG transport rate of $2 \cdot 0$ $\pm 0.27 \mathrm{nmol} / \mathrm{min} \times 10^{6}$ cells) (Fig. $4 \mathrm{G}$ ), progesterone (DOG transport rate of $2 \cdot 2 \pm 0.27 \mathrm{nmol} / \mathrm{min} \times 10^{6}$ cells) (Fig. $4 \mathrm{H}$ ), nor combined $17 \beta$-estradiol and progesterone treatment (DOG transport rate of $1.9 \pm 0.31 \mathrm{nmol} / \mathrm{min} \times$ $10^{6}$ cells) (Fig. $4 \mathrm{I}$ ) altered the rate of DOG transport (not significant). These results also correlate with the GLUT2 data obtained by Western blotting, where we saw no changes in GLUT2 expression.

To confirm the previous data, we tested whether hormone treatment altered the dose-response for DOG transport in these cells. The dose-response analysis of 


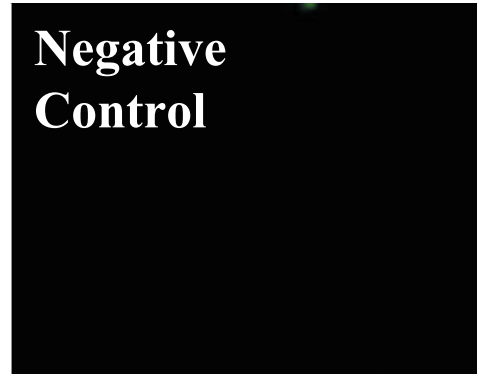

\section{GLUT1}
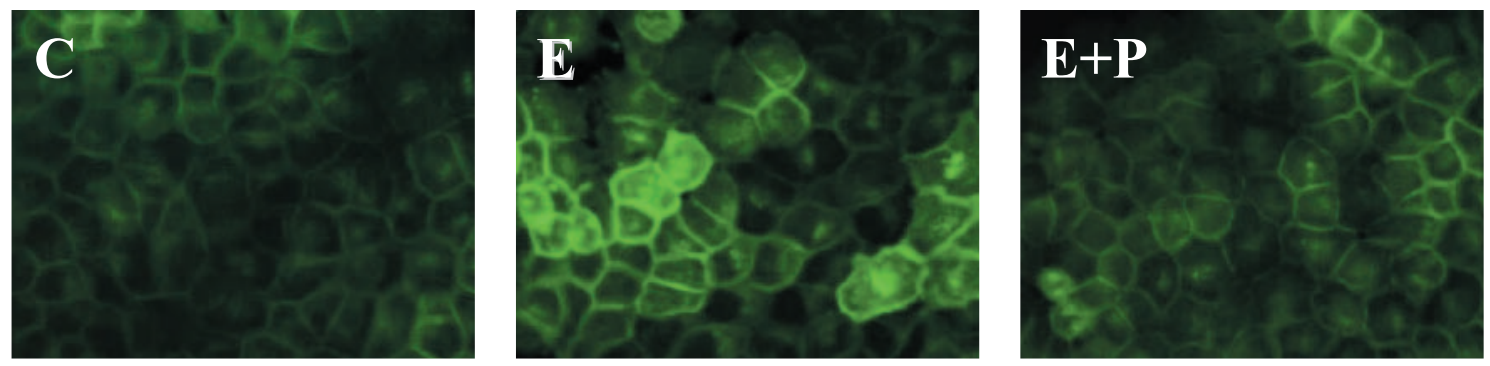

\section{GLUT3}
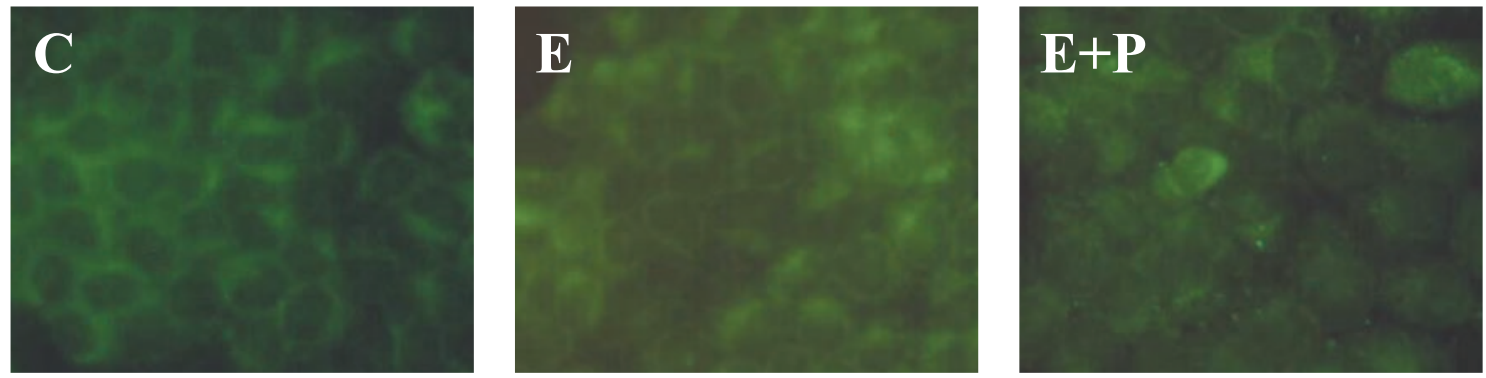

\section{GLUT4}
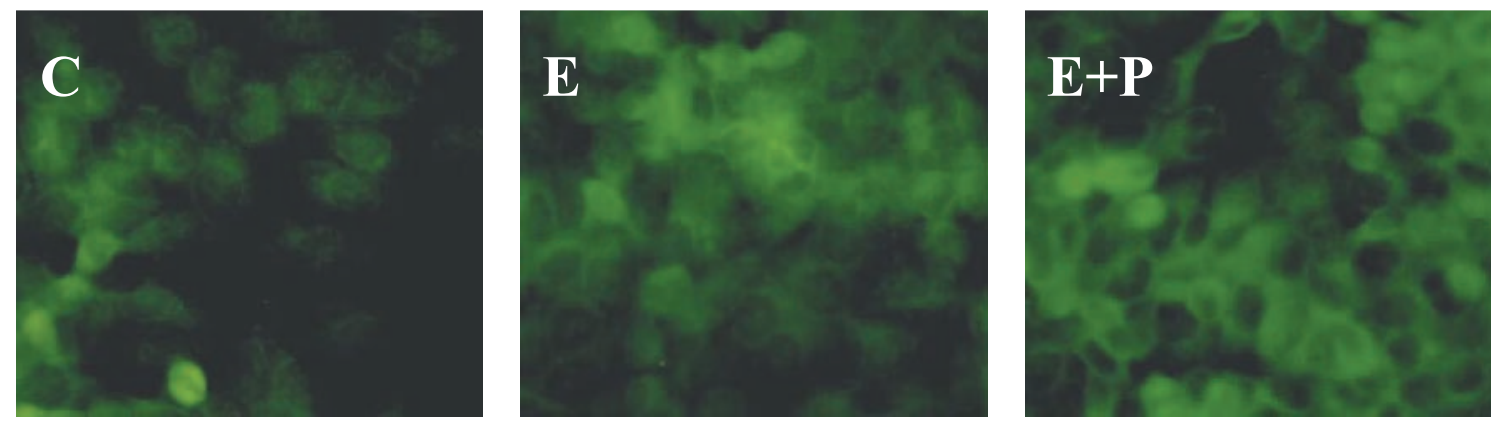

Figure 2 Immunocytochemistry for GLUT protein expression in control and hormone-treated Ishikawa cells. Immunocytochemistry showing the effect of 24-h incubation with $10 \mathrm{nM}$ estrogen (E) and $10 \mathrm{nM}$ estrogen $+10 \mathrm{nM}$ progesterone (E+P) on GLUT1, GLUT3 and GLUT4 expression. Control cells (C) were incubated with a corresponding volume of ethanol which was the vehicle used to solubilize the hormones. The negative control is the primary GLUT1 antibody pre-absorbed with the peptide used to raise it. 


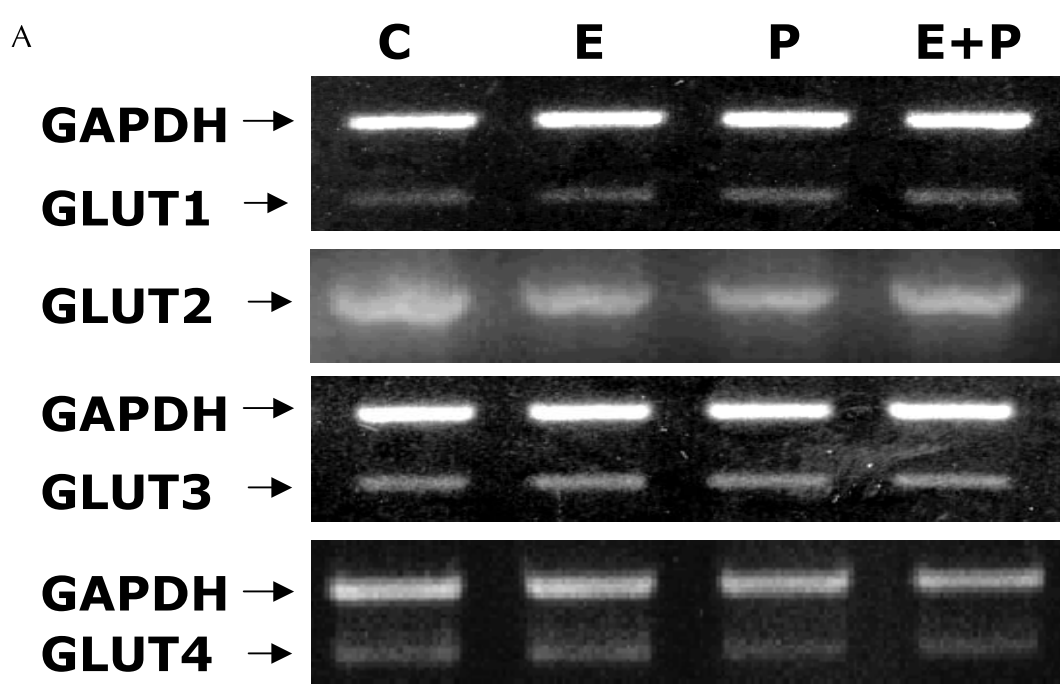

B

GLUT1

GLUT3

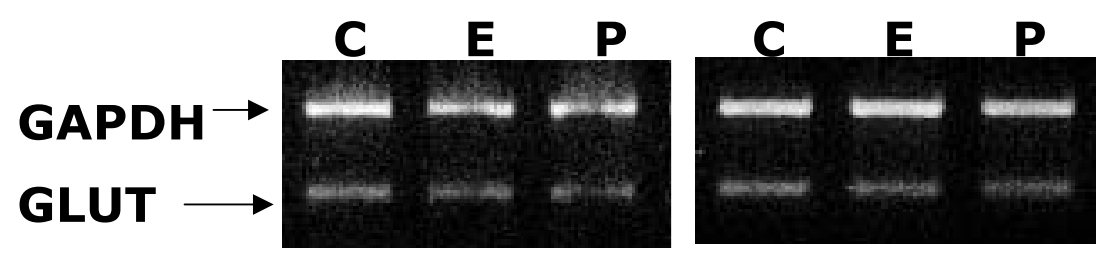

C
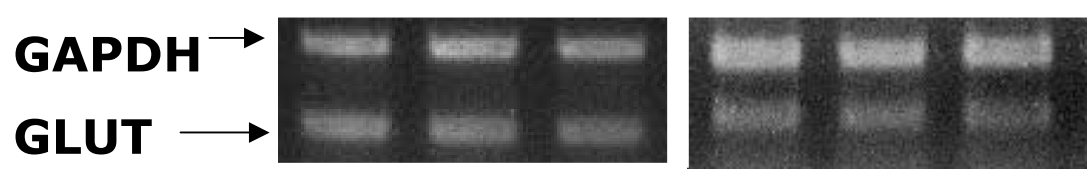

D

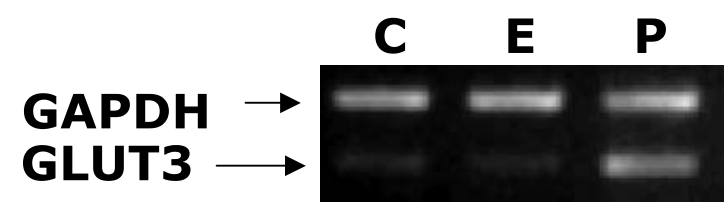

Figure 3 RT-PCR of GLUT mRNA expression in control and hormone-treated cells. (A) Ethidium bromide-stained agarose gels showing the effect of 9-h incubation with $10 \mathrm{nM}$ estrogen (E), $10 \mathrm{nM}$ progesterone (P) and $10 \mathrm{nM}$ estrogen $+10 \mathrm{nM}$ progesterone (E+P) on GLUT1, GLUT2, GLUT3 and GLUT4 expression in Ishikawa cells. (B) Ethidium

bromide-stained agarose gels showing the effect of 6-h incubation with $10 \mathrm{nM}$ estrogen (E) and $10 \mathrm{nM}$ progesterone (P) on GLUT1 and GLUT3 expression in Ishikawa cells. (C) Ethidium bromide-stained agarose gels showing the effect of 24-h incubation with $10 \mathrm{nM}$ estrogen (E) and $10 \mathrm{nM}$ progesterone (P) on GLUT1 and GLUT3 expression in Ishikawa cells. (D) As a positive control for hormonal regulation of mRNA, we show an ethidium bromide-stained agarose gel showing the effect of 9-h incubation with $10 \mathrm{nM}$ estrogen (E) and $10 \mathrm{nM}$ progesterone (P) on GLUT3 expression in ZR-75 cells. GAPDH was used as a loading control. Control cells $(C)$ were incubated with a corresponding volume of ethanol.

DOG transport in Ishikawa cells showed that transport approached saturation at approximately $60 \mathrm{mM}$ and that this was not affected by $17 \beta$-estradiol, progesterone or $17 \beta$-estradiol plus progesterone treatments (Fig. 5A).
However, the apparent total maximum transport velocity $\left(\mathrm{V}_{\text {max }}\right)$ was significantly increased by $17 \beta$-estradiol treatment: from $9 \cdot 4 \pm 0.3 \mathrm{nmol} / \mathrm{min} \times 10^{6}$ cells in the control cells to $13.9 \pm 0.5 \mathrm{nmol} / \mathrm{min} \times 10^{6}$ cells in $17 \beta$-estradiol- 


\section{$0.1 \mathrm{mM}$ DOG}
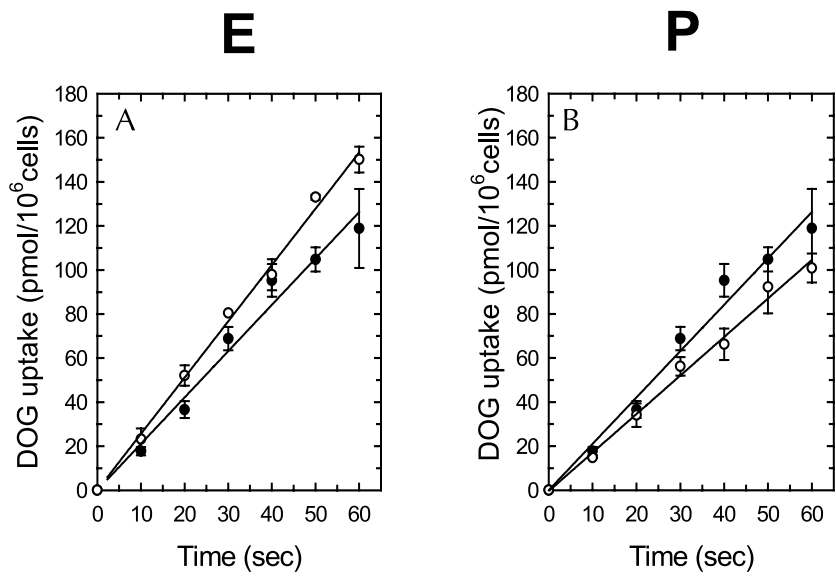

$E+P$
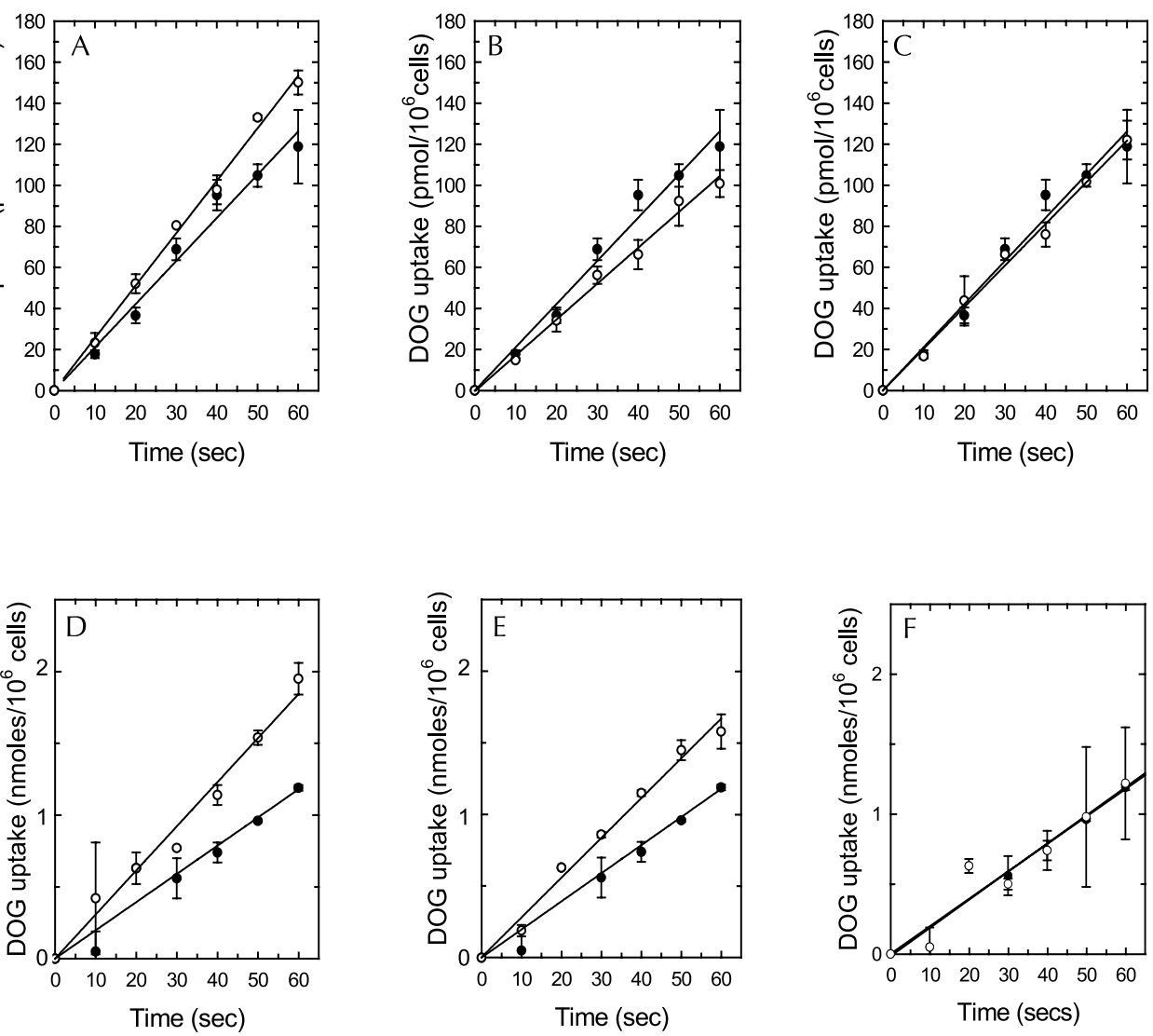

\section{$5 \mathrm{mM}$ DOG}
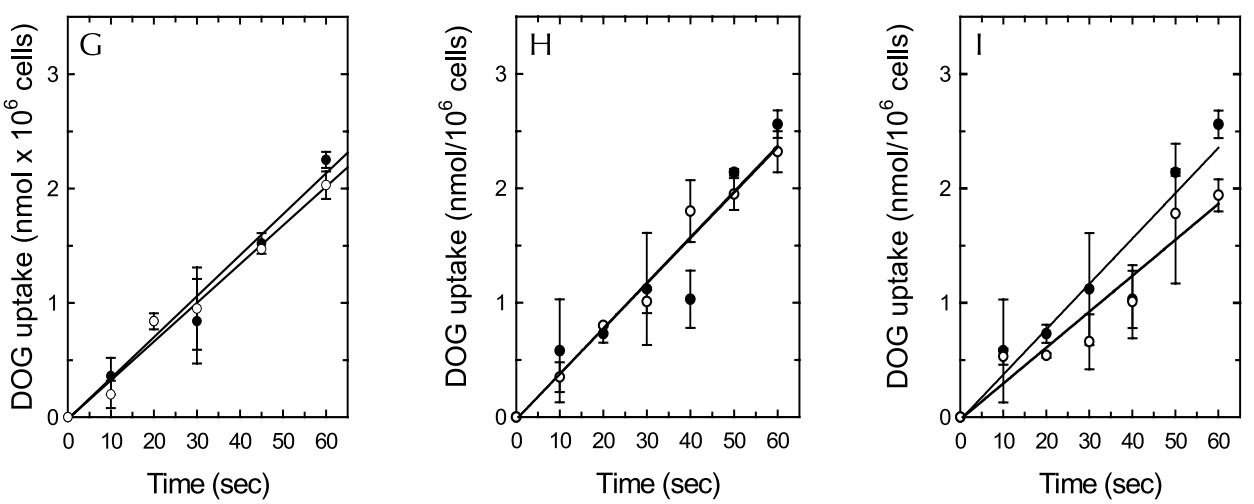

Figure 4 Time-course of deoxyglucose uptake in control and hormone-treated Ishikawa cells. (A-C) Effect of 24-h incubation with $10 \mathrm{nM}$ estrogen (A), $10 \mathrm{nM}$ progesterone (B) and $10 \mathrm{nM}$ estrogen $+10 \mathrm{nM}$ progesterone $(C)$ on the uptake of $0 \cdot 1 \mathrm{mM}$ DOG versus control. (D-F) Effect of 24-h incubation with $10 \mathrm{nM}$ estrogen (D), $10 \mathrm{nM}$ progesterone (E) and $10 \mathrm{nM}$ estrogen $+10 \mathrm{nM}$ progesterone (F) on the uptake of $5 \mathrm{mM}$ DOG versus control. (G-l) Effect of 24-h incubation with $10 \mathrm{nM}$ estrogen (G), $10 \mathrm{nM}$ progesterone $(\mathrm{H})$ and $10 \mathrm{nM}$ estrogen $+10 \mathrm{nM}$ progesterone $(\mathrm{I})$ on the uptake of $15 \mathrm{mM}$ DOG versus control. Control cells (C) were incubated with a corresponding volume of ethanol. Control cells are represented by closed circles; treated cells are represented by open circles. Transport experiments were performed at room temperature. Data represent the mean \pm the standard deviation of experiments performed in triplicate. $\mathrm{E}$, estrogen; $\mathrm{P}$, progesterone; $\mathrm{E}+\mathrm{P}$, estrogen plus progesterone. 

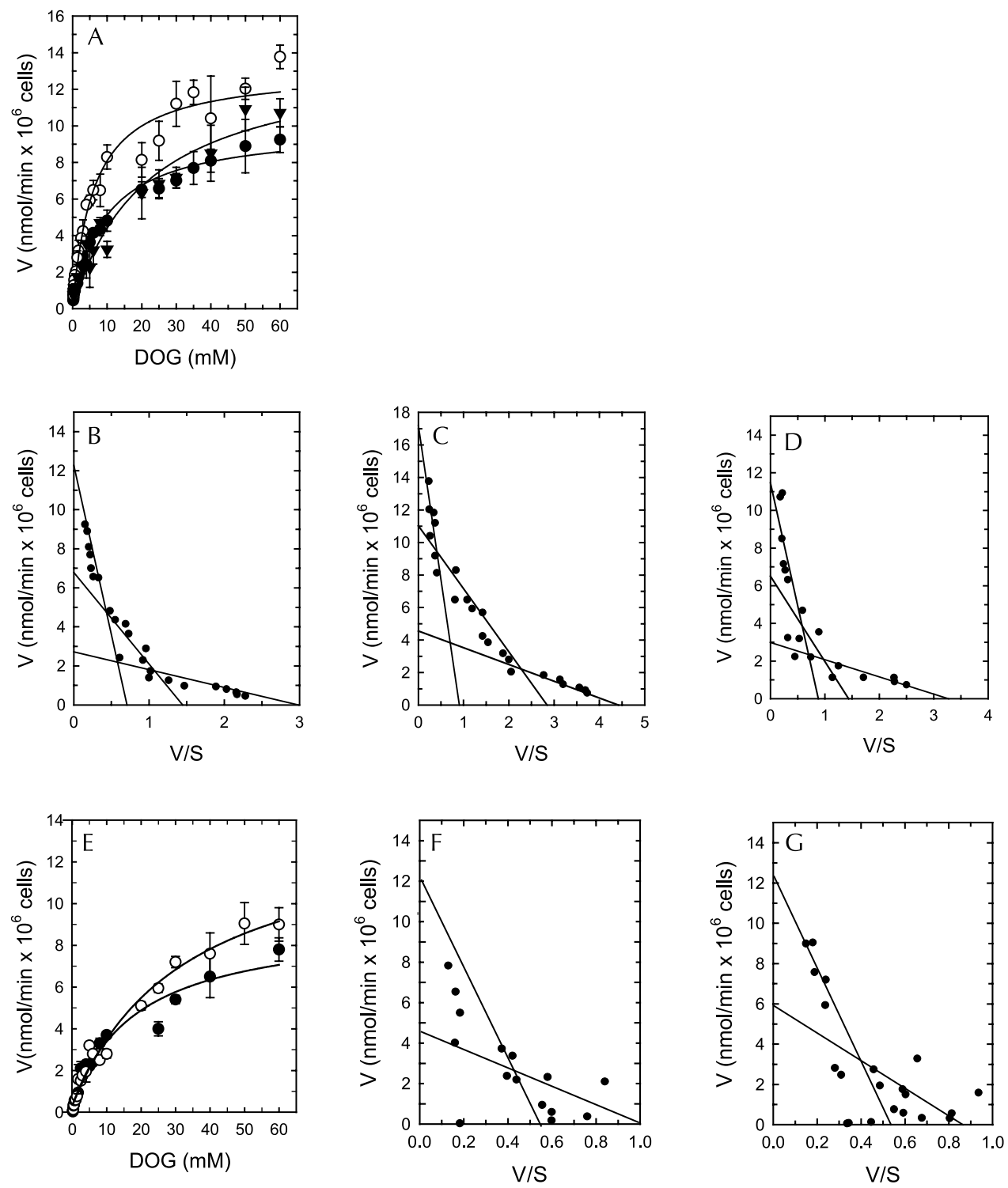

Figure 5 Dose-response analysis and substrate dependency of deoxyglucose transport in control and hormone-treated Ishikawa cells. (A) Dose-response analysis of DOG transport under control conditions (closed circles) in cells treated with $10 \mathrm{nM} 17 \beta$-estradiol (open circles) and in cells treated with $10 \mathrm{nM}$ $17 \beta$-estradiol + $10 \mathrm{nM}$ progesterone (triangles). (B) Eadie-Hofstee plot of the substrate dependence for DOG transport under control conditions. (C) Eadie-Hofstee plot of the substrate dependence for DOG transport after 24-h treatment with $10 \mathrm{nM} 17 \beta$-estradiol. (D) Eadie-Hofstee plot of the substrate dependence for DOG transport after 24-h treatment with $10 \mathrm{nM} 17 \beta$-estradiol+10 nM progesterone. (E) Dose-response analysis of DOG transport under control conditions (closed circles) and in cells treated with $10 \mathrm{nM}$ progesterone (open circles). (F) Eadie-Hofstee plot of the substrate dependence for DOG transport under control conditions. (G) Eadie-Hofstee plot of the substrate dependence for DOG transport after 24-h treatment with $10 \mathrm{nM}$ progesterone. Control cells were incubated with a corresponding volume of ethanol. Transport experiments were performed at room temperature. Data represent the mean \pm the standard deviation of experiments performed in triplicate.

treated cells $(P<0 \cdot 05$; Fig. 4A). Treatment with $17 \beta$ estradiol plus progesterone returned the $\mathrm{V}_{\max }$ to control levels $\left(10 \cdot 3 \pm 0 \cdot 7 \mathrm{nmol} / \mathrm{min} \times 10^{6}\right.$ cells $)$ (Fig. $\left.5 \mathrm{~A}\right)$, confirming that $17 \beta$-estradiol treatment increased the transport capacity of the Ishikawa cells and that the concomitant addition of progesterone abolished this effect. 
Analysis of the transport data using the Eadie-Hofstee method rendered a curve that could be resolved into three different components (Fig. 5B-D). This indicates the presence of at least three different transporters, each having a different affinity for the substrate, involved in the transport of DOG in the control as well as in the hormone-treated cells. Moreover, a detailed observation of the data revealed that hormone treatment differentially affected each functional component. The higher affinity component was clearly identifiable in the untreated control cells, and had an apparent, uncorrected $K_{\mathrm{m}}$ of $0 \cdot 8$ $\pm 0.1 \mathrm{mM}$ and $\mathrm{a} \mathrm{V}_{\max }$ of $2.3 \pm 0.6 \mathrm{nmol} / \mathrm{min} \times 10^{6}$ cells (Fig. 5B). This component showed an increase in transport $\mathrm{V}_{\max }$ (to $4.9 \pm 0.8 \mathrm{nmol} / \mathrm{min} \times 10^{6}$ cells; $P<0 \cdot 05$ ) in the $17 \beta$-estradiol-treated cells, without changes in the transport $K_{\mathrm{m}}$ (apparent uncorrected $K_{\mathrm{m}}$ of $1 \cdot 1 \pm 0 \cdot 2 \mathrm{mM}$ ) (Fig. 5C). Combination treatment again caused a decrease in transport $\mathrm{V}_{\max }$ back to control levels $(3.0 \pm 0.5 \mathrm{nmol} /$ min $\times 10^{6}$ cells; not significant compared with control) without changes in the transport $K_{\mathrm{m}}$ (apparent uncorrected $K_{\mathrm{m}}$ of $0.9 \pm 0.2 \mathrm{mM}$ ) (Fig. 5D). This transport $K_{\mathrm{m}}$ is in the range of that expected for GLUT3. However, since GLUT3 protein expression levels, as detected by Western blotting and immunocytochemistry, are so low, it is difficult to correlate the changes in transport produced by hormonal treatments to changes in protein expression. The intermediate affinity component had an apparent, uncorrected $K_{\mathrm{m}}$ of $4.4 \pm 0.5 \mathrm{mM}$ and a $\mathrm{V}_{\max }$ of 6.5 $\pm 0.8 \mathrm{nmol} / \mathrm{min} \times 10^{6}$ cells under control conditions (Fig. 5B). This component showed a clear increase in transport $\mathrm{V}_{\max }$ (to $10.3 \pm 1.4 \mathrm{nmol} / \mathrm{min} \times 10^{6}$ cells; $P<0 \cdot 05)$ in the $17 \beta$-estradiol-treated cells, without changes in the transport $K_{\mathrm{m}}$ (apparent uncorrected $K_{\mathrm{m}}$ of $3.8 \pm 0.4 \mathrm{mM}$ ) (Fig. 5C). Combination treatment again caused a decrease in transport $\mathrm{V}_{\max }$ back to control levels $\left(6.6 \pm 0.6 \mathrm{nmol} / \mathrm{min} \times 10^{6}\right.$ cells $)$ without changes in the transport $K_{\mathrm{m}}$ (apparent uncorrected $K_{\mathrm{m}}$ of $4.5 \pm 0 \cdot 8 \mathrm{mM}$ ) (Fig. 5D). The transport $K_{\mathrm{m}}$ of the intermediate affinity component corresponds to the expected properties of GLUT1 (and GLUT4), and therefore the increased activity of this component in the $17 \beta$-estradiol-treated cells, and subsequent decrease in combination-treated cells, is also consistent with the observed regulation of GLUT1 protein expression detected by Western blotting, immunocytochemistry and flow cytometry. The lower affinity component had functional properties similar to those of the low-affinity glucose transporter GLUT2, with uncorrected apparent $K_{\mathrm{m}} \mathrm{s}$ of $17 \cdot 6,19 \cdot 6$ and $15.1 \mathrm{mM}$ for the transport of DOG in the control, $17 \beta$-estradiol- and the combination-treated cells respectively. Moreover, there were no changes in the apparent transport $\mathrm{V}_{\max }$ in the $17 \beta$-estradiol- $(11 \cdot 4 \pm$ $1.6 \mathrm{nmol} / \mathrm{min} \times 10^{6}$ cells) or the combination-treated cells $\left(11.4 \pm 1.3 \mathrm{nmol} / \mathrm{min} \times 10^{6}\right.$ cells $)$ compared with the untreated control cells $\left(12 \cdot 8 \pm 1.7 \mathrm{nmol} / \mathrm{min} \times 10^{6}\right.$ cells $)$ (Fig. 5B-D). The lack of a functional effect of the hormone treatment on the activity of the lower affinity component is consistent with the lack of an effect on GLUT2 expression detected by Western blotting.

Since the progesterone experiment was carried out separately, it had a separate control from the estrogen and estrogen plus progesterone experiment. In this experiment transport was also saturated at $60 \mathrm{mM} \mathrm{DOG}$ and this was not affected by progesterone treatment (Fig. 5E). The apparent total $\mathrm{V}_{\max }$ was slightly increased by progesterone treatment, from $11.8 \pm 0.9 \mathrm{nmol} / \mathrm{min} \times 10^{6}$ cells to 12.6 $\pm 1 \cdot 1 \mathrm{nmol} / \mathrm{min} \times 10^{6}$ cells; however, this did not reach statistical significance (Fig. 5E).

Analysis of the transport data in this set of experiments using the Eadie-Hofstee method rendered a curve that could be resolved into only two different components (Fig. $5 F, G)$. This was due to the predominance of the intermediate affinity component which masked the possible presence of a high affinity component. These data indicates the presence of at least two different transporters, each having a different affinity for the substrate, involved in the transport of DOG in the control as well as the progesterone-treated cells. The intermediate affinity component had an apparent, uncorrected $K_{\mathrm{m}}$ of $4.5 \pm 0.8 \mathrm{mM}$ and a $\mathrm{V}_{\max }$ of $4.6 \pm 0.4 \mathrm{nmol} / \mathrm{min} \times 10^{6}$ cells under control conditions (Fig. 5F). This component showed a significant increase in transport $\mathrm{V}_{\max }$ (to $6.0 \pm 0.5 \mathrm{nmol} /$ $\min \times 10^{6}$ cells; $\left.P<0 \cdot 05\right)$ in the progesterone-treated cells, without changes in the transport $K_{\mathrm{m}}$ (apparent uncorrected $K_{\mathrm{m}}$ of $6.0 \pm 0.9 \mathrm{mM}$ ) (Fig. $5 \mathrm{G}$ ). These transport data corresponds to increases in GLUT1 protein expression observed in the presence of progesterone. As was the case with estrogen and estrogen plus progesterone treatments, progesterone alone did not cause any changes in the transport mediated by the low-affinity component (Fig. 5F,G).

Western blot analysis clearly showed that, in Ishikawa cells, GLUT2 expression is extremely low (Figs 1A and $6 \mathrm{~B})$, yet this cell line expresses a low-affinity transport component that has a considerable capacity to transport DOG (Fig. 6A). RT-PCR studies showed that these cells also express GLUT6 transcript, a transporter with a similar $K_{\mathrm{m}}$ for DOG transport as GLUT2 (Fig. 6C). Therefore, a possible explanation for the low-affinity transport observed in Ishikawa cells is that it is mediated by GLUT6, and not GLUT2.

\section{Discussion}

Uterine cells from different origins display different GLUT isoform expression patterns. A study of GLUT expression in immature rat uterus only detected the presence of GLUT1 and GLUT4 isoforms (Welch \& Gorski 1999), while in the human endometrium only GLUT1 and GLUT3 have been reported (Younes et al. 1997, von Wolff et al. 2003). In Ishikawa endometrial 
A

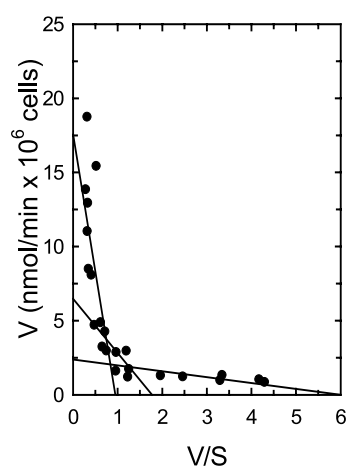

B

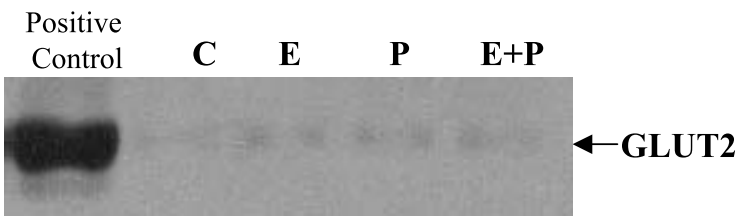

C

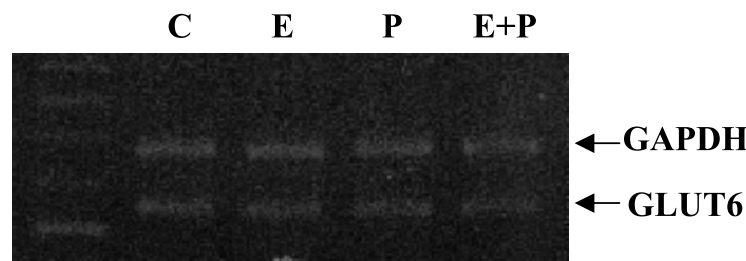

Figure 6 GLUT2 and GLUT6 expression in hormone-treated Ishikawa cells. (A) Eadie-Hofstee plot of the substrate dependence for DOG transport under control conditions. (B) Western blots showing the effect of 24-h incubation with $10 \mathrm{nM}$ estrogen (E), $10 \mathrm{nM}$ progesterone $(\mathrm{P})$ and $10 \mathrm{nM}$ estrogen $+10 \mathrm{nM}$ progesterone $(\mathrm{E}+\mathrm{P})$ on GLUT2 expression in Ishikawa cells. (C) Ethidium bromide-stained agarose gels showing the effect of 9-h incubation with $10 \mathrm{nM}$ estrogen $(\mathrm{E}), 10 \mathrm{nM}$ progesterone $(\mathrm{P})$ and $10 \mathrm{nM}$ estrogen + $10 \mathrm{nM}$ progesterone $(\mathrm{E}+\mathrm{P})$ on GLUT6 mRNA expression in Ishikawa cells. GAPDH (upper band) was used as a loading control. Control cells $(C)$ were incubated with a corresponding volume of ethanol vehicle.

cancer cells we detected the expression of GLUT1-4 and GLUT6. To our knowledge, this is the first report of GLUT2 expression in the cells of endometrial origin. This expression of glucose transporters, which is not observed in normal tissue, has been widely reported and may be a mechanism utilized by the cancer cell to obtain the extra energy needed for processes such as angiogenesis, proliferation and metastasis (Medina \& Owen 2002). Clinical observations demonstrate that estrogen acts as a proliferative agent on the endometrial epithelium. Unopposed estrogen treatment, while delivering beneficial relief from post-menopausal symptoms, also results in endometrial disorders such as endometriosis and cancer (Smith et al. 1975, Berger \& Fowler 1997). To circumvent these side effects, progesterone is now added to remove the endometrial risks (Hulka \& Brinton 1995, Persson 2000, Schairer et al. 2000). This strategy is also employed in the majority of oral contraceptive formulations (Henderson \& Feigelson 2000).

Herein we studied the expression and regulation of GLUT1-4 in response to hormonal treatments and correlate changes in expression to changes in glucose transport in the human endometrial epithelial cancer cell line, Ishikawa. We found that these cells express GLUT1-4 isoforms to varying degrees. Analysis of regulation reveals that GLUT1 protein expression was increased by $17 \beta-$ estradiol and by progesterone; however, combined $17 \beta$-estradiol and progesterone treatment abolished the observed regulatory effects produced when these hormones are present individually. GLUT2 and GLUT3 proteins are both expressed at very low levels. GLUT4 protein levels are possibly upregulated in response to all hormonal treatments. None of the hormonal treatments affected mRNA levels. Transport kinetic studies show that Ishikawa cells have at least three glucose transport components with transport characteristics corresponding to GLUT1/4, GLUT2/6 and GLUT3. We demonstrated a direct correlation between GLUT1-4 isoform expression and glucose transport, although the relative contributions of GLUT1 and GLUT4 could not be separated because of overlapping $K_{\mathrm{m}} \mathrm{s}$.

The observation that estrogen and progesterone individually increase GLUT1 expression, while the combination of both hormones causes a complete reverse in expression patterns is surprising, but by no means unique to this situation. Although the purpose of this paper was to dissect the role of estrogen and progesterone individually, in vivo these hormones are never present without the other. During the luteal phase of the menstrual cycle both estrogen and progesterone are present in high levels. The challenge for future experimentation is to understand the process of cross-talk by which two hormones, working individually in one direction, can change when in combination. This has important clinical implications as it is now evident that we cannot predict the response of exogenous progesterone preparations based on the effect of progesterone in the presence of estrogen.

Interestingly, despite marked protein regulation, our results show that GLUT1-4 mRNA expression does not change in response to 6,9 or $24 \mathrm{~h}$ of hormonal treatment in the endometrial epithelium-derived Ishikawa cell line. However, the failure to observe any hormonal regulation on GLUT1-4 mRNA in these epithelium-derived cancer cells is not unexpected. von Wolff et al. (2003) reported increases in GLUT1 and GLUT3 mRNA expression in total normal human endometrium throughout the secretory phase of the menstrual cycle, in which estrogen and progesterone levels are high. However, a more detailed analysis revealed that these increases were not caused by changes in GLUT expression in endometrial epithelial 
cells, but were actually caused by increased expression in stromal cells. Welch and Gorski (1999) also reported increases in rat uterine GLUT1 mRNA after $6 \mathrm{~h}$ of estrogen treatment, an effect which disappeared after $8 \mathrm{~h}$ of estrogen treatment. However, these results are also derived from total uterine preparations, and therefore it is impossible to determine if there was an effect on the endometrial epithelial cells. Moreover, there are extensive data in the literature indicating that changes in mRNA, from a variety of genes, in endometrial tissue can only be detected after long-term ( $2-5$ days) treatments (Lockwood et al. 1993, Sakata et al. 1998, Darnel et al. 1999, Christian et al. 2001, Mak et al. 2002). It is most likely that the changes we observed in GLUT protein were being caused by post-transcriptional modifications, such as increased translational rates or post-translational changes that affect protein stability.

Any proliferating cell, including cancer, requires an increased energy supply to sustain the proliferation process. There is little information in the literature regarding GLUT expression in malignant endometrial epithelium; however, one study demonstrated overexpression of GLUT1 in endometrial adenocarcinomas (Wang et al. 2000). This observation suggests that GLUT1 is utilized by endometrial cancer cells to obtain energy. Since we observed that increased expression was associated with increased transport in this cell line, we can infer that at least some of the increased GLUT protein is being expressed at the plasma membrane where it has access to circulating glucose.

One of the disadvantages of DOG transport studies is that GLUT1 and GLUT4 have $K_{\mathrm{m}} \mathrm{s}$ in the same range; therefore, it is not possible to differentiate the individual contribution of these transporters to the transport kinetics. However, although it is likely that both GLUT1 and GLUT4 are contributing to DOG transport in these cells, the protein expression data support a role for GLUT1 as the main glucose transporter affected by hormonal treatment. Despite this, it is more than likely that the other GLUTs expressed in these cells are also contributing to glucose transport. In relation to this issue, we show that in Ishikawa cells GLUT2 expression is extremely low, yet this cell line expresses a low affinity transport component which has a considerable capacity to transport DOG. RT-PCR studies show that these cells also express mRNA for GLUT6, a low-affinity transporter. Therefore, the low-affinity transport observed in Ishikawa cells may be mediated by GLUT6, and not GLUT2 (Fig. 6). Welch and Gorski (1999) reported that they observed an increase in glucose uptake after $30 \mathrm{~min}$ of estrogen treatment. At time periods under $4 \mathrm{~h}$ of estrogen treatment, that study did not report any changes in GLUT mRNA or protein expression. The authors also ruled out GLUT protein translocation as a mechanism responsible for the increased glucose transport and speculated that changes in GLUT activation are responsible for the increased glucose trans- port observed at short time periods of estrogen treatment (Welch and Gorski 1999). Since that study measured accumulation of phosphorylated DOG and not DOG transport, it is possible that the changes observed in DOG accumulation were caused by changes in hexokinase activity as well as, or rather than, changes in transporter activity. Our transport studies were carried out at short time periods (10-60 s) and therefore only measured the DOG transport component.

We postulate that hormonally induced increases in glucose transport confer a survival advantage to the growing cancer cell, in the form of greater accessibility to available glucose. This theory is in line with clinical observations where estrogen therapy increased the incidence of endometrial cancer and that this increase in incidence was reduced when progesterone was added to the hormonal preparations (Smith et al. 1975, Berger \& Fowler 1997) and is also supported by the observation that GLUT1 is overexpressed in biopsies from cancers from the majority of estrogen and progesterone target tissues, such as breast, endometrium, cervix and ovary (Kang et al. 2002, Medina \& Owen 2002). Similar results are available which correlate hormonal effects on GLUT expression and glucose transport in ZR-75 breast cancer cells to breast cancer incidence (Medina et al. 2003). Furthermore, overexpression of GLUT2 has not been reported in cancers originating from steroid hormone target tissues (Medina \& Owen 2002), nor was an alteration in GLUT2 observed in Ishikawa cells in response to hormonal administration. An absence of effect in GLUT2 protein or RNA levels corresponded to an absence of alteration in glucose transport at the $K_{\mathrm{m}}$ corresponding to GLUT2/6.

We also demonstrated that progesterone caused an increase in GLUT1 expression and GLUT1-mediated glucose transport. Unfortunately, data on the action of progestins alone in endometrial cancer patients are both very limited and contradictory. Our data unequivocally show that progesterone treatment, on its own, caused an increase in GLUT1 expression and GLUT1-mediated glucose transport in Ishikawa endometrial cancer cells. This suggests that, at least in this cell line, progesterone has the potential to promote a proliferation-inducing environment.

In summary, we present an in vitro model in which to study the effects of estrogen and progesterone treatment in endometrial cancer. We have also shown that, when estrogen and progesterone are administered individually, GLUT expression and the corresponding rate of glucose transport increase, effects which disappear when these hormones are administered concomitantly. We speculate that an increase in GLUT expression in the presence of the different hormonal preparations confers a survival advantage to the burgeoning endometrial cancer cell and thus increases the incidence of endometrial cancer. We propose that components which are involved in the regulation of GLUT expression and subsequent glucose transport could 
be exploited as important future pharmaceutical or gene therapy targets to treat endometrial cancers which do not respond to more traditional treatments.

\section{Funding}

This work was partially supported by grant DI 01-03 (R A M) from the Dirección de Investigación, Universidad Nacional Andrés Bello, Santiago, Chile; grants 1020451 (J C V), 1010843 (F N), 1020715 (G I O) from FONDECYT, Chile; grant 206.034.006-1.4 from the Dirección de Investigación, Universidad de Concepción, Concepción, Chile, and grant C-13685 (G I O) from the Fundación Andes, Chile.

\section{References}

Berger GS \& Fowler WC Jr 1997 Exogenous estrogens and endometrial carcinoma: review and comments for the clinician. Journal of Reproductive Medicine 18 177-180.

Binder C, Binder L, Marx D, Schauer A \& Hiddemann W 1997 Deregulated simultaneous expression of multiple glucose transporter isoforms in malignant cells and tissues. Anticancer Research 17 4299-4304.

Chomczynski P 1992 One-hour downward alkaline capillary transfer for blotting of DNA and RNA. Analytical Biochemistry 201 134-139.

Christian M, Marangos P, Mak I, McVey J, Barker F, White J \& Brosens JJ 2001 Interferon- $\gamma$ modulates prolactin and tissue factor expression in differentiating human endometrial stromal cells. Endocrinology 142 3142-3151.

Darnel AD, Archer TK \& Yang K 1999 Regulation of 11 beta-hydroxysteroid dehydrogenase type 2 by steroid hormones and epidermal growth factor in the Ishikawa human endometrial cell line. Journal of Steroid Biochemistry and Molecular Biology 70 203-210.

Henderson BE \& Feigelson HS 2000 Hormonal carcinogenesis. Carcinogenesis 21 427-433.

Henderson BE, Ross RK, Pike MC \& Cassagrande JT 1982 Endogenous hormones as a major risk factor in human cancer. Cancer Research 24 3232-3239.

Hulka BS \& Brinton LA 1995 Hormones and breast and endometrial cancers: preventive strategies and future research. Environmental Health Perspectives 103 (Suppl 8) 185-189.

Joost HG \& Thorens B 2001 The extended GLUT-family of sugar/polyol transport facilitators: nomenclature, sequence characteristics, and potential function of its novel members. Molecular Membrane Biology 18 247-256.

Kang SS, Chun YK, Hur MH, Lee HK, Kim YJ, Hong SR, Lee JH, Lee SG \& Park YK 2002 Clinical significance of glucose transporter 1 (GLUT1) expression in human breast carcinoma. Japanese Journal of Cancer Research 93 1123-1128.

Key TJA \& Pike MC 1988 The dose-effect relationship between 'unopposed' estrogens and endometrial mitotic rate: its central role in explaining and predicting endometrial cancer risk. British Journal of Cancer 57 205-212.
Lockwood CJ, Nemerson Y, Guller S, Krikun G, Alvarez M, Hausknecht V, Gurpide E \& Schatz F 1993 Progestational regulation of human endometrial stromal cell tissue factor expression during decidualization. Journal of Clinical Endocrinology and Metabolism 76 231-236.

Mak IY, Brosens JJ, Christian M, Hills FA, Chamley L, Regan L \& White JO 2002 Regulated expression of signal transducer and activator of transcription, Stat5, and its enhancement of PRL expression in human endometrial stromal cells in vitro. Journal of Clinical Endocrinology and Metabolism 87 2581-2588.

Medina RA \& Owen GI 2002 Glucose transporters: expression, regulation and cancer. Biological Research 35 9-26.

Medina RA, Meneses AM, Vera JC, Guzman C, Nualart F, Astuya A, García MA, Kato S, Carvajal A \& Pinto M 2003 Estrogen and progesterone upregulate glucose transporter expression in ZR-75-71 human breast cancer cells. Endocrinology 144 4527-4535.

Nualart F, Godoy A \& Reinicke K 1999 Expression of the hexose transporters GLUT1 and GLUT2 during the early development of the human brain. Brain Research 824 97-104.

Persson I 2000 Estrogens in the causation of breast, endometrial and ovarian cancers - evidence and hypotheses from epidemiological findings. Journal of Steroid Biochemistry and Molecular Biology $\mathbf{7 4}$ 357-364.

Sakata M, Kurachi H, Morishige K, Ogura K, Yamaguchi M, Nishio Y, Ikegami H, Miyake A \& Murata Y 1998 Messenger RNA differential display reverse-transcriptase-polymerase-chain-reaction analysis of a progestogen-suppressive gene in a human endometrial-cancer cell line. International Journal of Cancer $\mathbf{7 8}$ 125-129.

Schairer C, Lubin J, Trois R, Sturgeon S, Brinton L \& Hoover R 2000 Menopausal estrogen and estrogen-progestin replacement therapy and breast cancer risk. Journal of the American Medical Association 283 485-491.

Smith DC, Prentice R, Thompson DJ \& Herrmann WL 1975 Association of exogenous estrogen and endometrial carcinoma. New England Journal of Medicine 293 1164-1167.

Takagi H, Tanihara H, Seino Y \& Yoshimura N 1994 Characterization of glucose transporter in cultured human retinal pigment epithelial cells: gene expression and effect of growth factors. Investigations in Ophthalmological and Visual Science $\mathbf{3 5}$ 170-177.

Wang BY, Kalir T, Sabo E, Sherman DE, Cohen C \& Burstein DE 2000 Immunohistochemical staining of GLUT1 in benign, hyperplastic, and malignant endometrial epithelial Cancer $\mathbf{8 8}$ 2778-2781.

Welch RD \& Gorski J 1999 Regulation of glucose transporters by estradiol in the immature rat uterus. Endocrinology 140 3602-3608.

von Wolff M, Ursel S, Hahn U, Steldinger R \& Strowitzki T 2003 Glucose transporter proteins (GLUT) in human endometrium: expression, regulation, and function throughout the menstrual cycle and in early pregnancy. Journal of Clinical Endocrinology and Metabolism 88 3885-3892.

Younes M, Lechago LV, Somoano JR, Mosharaf M \& Lechago J 1997 Immunohistochemical detection of Glut3 in human tumours and normal tissues. Anticancer Research 17 2747-2750.

Received in final form 15 June 2004

Accepted 18 June 2004 